\title{
Exploration of Teaching Reform of Drug and Food Major
}

\author{
Qing-Song LI 1,2,3,a , Yuan MENG ${ }^{4, b}$, Ruo-Kun $\mathrm{YI}^{1,2,3, \mathrm{c}}$ and Xin ZHAO ${ }^{1,2,3, \mathrm{~d},{ }^{*}}$ \\ ${ }^{1}$ Department of Biological and Chemical Engineering, Chongqing University of Education, \\ Chongqing 400067, China \\ ${ }^{2}$ Chongqing Collaborative Innovation Center for Functional Food, Chongqing University of \\ Education, Chongqing 400067, China \\ ${ }^{3}$ ChongqingEngineering Research Center of Functional Food, Chongqing University of \\ Education, Chongqing 400067, China \\ ${ }^{4}$ Department of Ideological and Political Education, Chongqing University of Technology, \\ Chongqing 400054 \\ a602403962@qq.com, ’2388654426@qq.com, cyiruokun1214@hotmail.com, \\ dzhaoxin@cque.edu.cn \\ *Corresponding author
}

Keywords: university medicine and food major, educational model, educational model reform.

\begin{abstract}
In order to develop a strong ability to adapt and creativity, and cultivate the internationalization development of pharmaceutical and food professionals, improve the effectiveness and quality of teaching. High vocational designed school in drug and food professional teaching mode aspects from following several aspects for improved: First, arranges the class hour structure reasonably, second, completes the student to practice the work, third, the attraction fund investment and the attention, fourth, uses many teaching platform to stimulate aspects and so on student interest, improves the educational model, thus may give the student to increase the more powerful employment opportunity.
\end{abstract}

\section{Introduction}

Food industry is an indispensable one of important pillar industries in our national economic development, so does drug [1]. Therefore, to deepen the teaching reform in food major of higher vocational education is an important task for improving educational teaching quality, and providing high-quality professional talents. At present, the teaching reform in food major is extremely urgent due to the teaching situation and the student's employment direction of drug and food major in college and university. The teaching of college and university is composed of theoretical teaching and practical teaching. The former is the precondition and necessary condition for students to get knowledge. The latter is the necessary supplement for theoretical knowledge. In addition, practical teaching also can cultivate the students' ability of handling and operating as well as creative thinking while stimulating their interest to learn. The teaching goals in class can be realized only if practical teaching cooperates with theoretical teaching perfectly, namely realize the goal of knowledge and skill, the goal of process and method, and the goal of emotion, attitude and value.

\section{Analysis on Questionnaire for Teaching Model of Drug and Food Major in Colleges and Universities}

\section{Process of Investigation}

In order to better grasp the relevant data, a questionnaire survey has been made for the students learning drug and food major in a college. The contents are as follows. First, make an investigation for the basic information of those questioned, such as major, class, grade and main elective courses etc. Second, make an investigation for the comprehension degree of students for specialized 
knowledge. Third, make an investigation whether the course schedule of compulsory courses and optional courses is reasonable or not, and for the students' attitude for the major they learn. Fourth, make an investigation whether the arrangement for theoretical teaching and practical teaching is reasonable or not in students' opinion, and whether experimental facilities are sufficient or not. Last, make an investigation for the attendance rate of students etc.

\section{Analysis on Questionnaire}

\section{Students' Comprehension Degree for the Major They Learn}

For the students' comprehension degree for the major they learn, refer to Fig. 1. Most of students are interested in drug and food major very much. But they only have interest. For the specific contents, their understanding is very little. The above table shows students' understanding for specific functions and professional knowledge of food major is not clear. A large portion of students (58.5\%) do not understand their major at all, except a vague idea. There are only less than $15.2 \%$ students who choose their major based on their interest. In addition, these students are willing to have a thorough comprehension for their major.

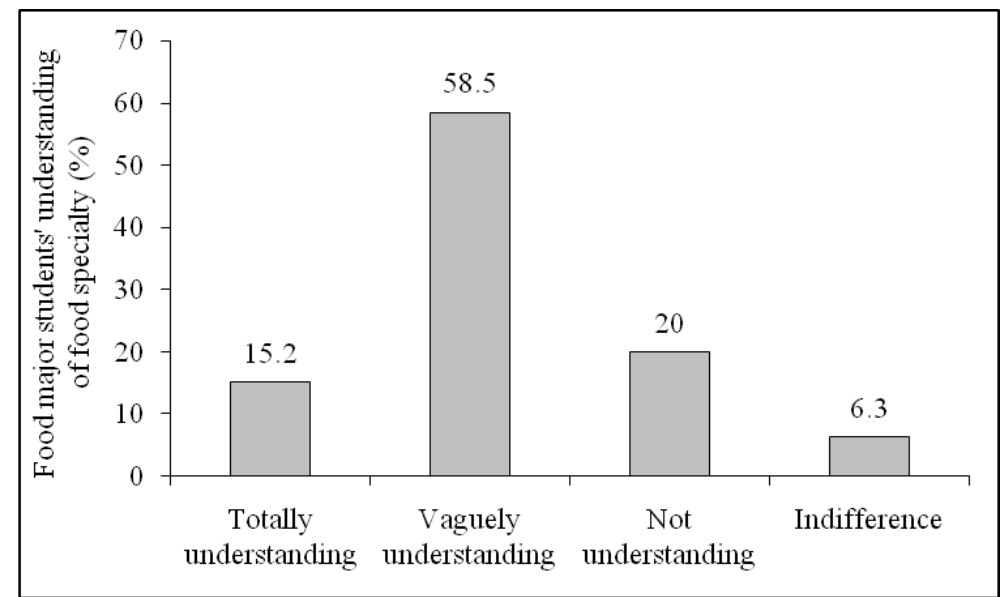

Fig.1. The food major students' understanding of food specialty.

\section{Investigation on Students' Opinion for Arrangement of Compulsory Course and Optional Course}

According to the investigation (Table 1), there are only 50\% students to agree such arrangement. Some students hold the opinion that some contents of compulsory course and optional course are repeated. Some teaching arrangement of compulsory course is not reasonable. Meanwhile, during their learning drug and food major in college, the students mainly learn the basic knowledge of food major as well as comprehensively get the industry situation. The unreasonable course arrangement will make students lack of some basic knowledge. This will result in the decrease of their interest, and not conducive to their own development. According to the investigation, $50 \%$ students listen carefully in the class for the compulsory course. Bur for optional course, it is an inevitable that a large portion of students will not listen carefully in the large class.

Table1. Teaching hours of compulsory courses and elective courses.

\begin{tabular}{ccc}
\hline Course & Teaching hour & Proportion (\%) \\
\hline Compulsory course/Each course & 32 & 61.5 \\
Elective course/Each course & $16-20$ & $30.7 \%-38.4$ \\
\hline
\end{tabular}




\section{Investigation on Students' Attendance Rate and Class Listening}

The investigation shows (Table 2, Fig. 2) that the teaching and the class listening effects of specialized course are not ideal. The students carefully listening in the class only account for one in four. Almost a half of students listen in the class carelessly. Sleeping and playing mobile in the class are very common, which has become a universal phenomenon. There are many reasons. But one point cannot be ignored. That is the traditional teaching mode is difficult to arouse students' enthusiasm to learn and listen carefully in the class. It cannot meet the diversified demand of students and the requirement of times for talent development. It is extremely urgent to find the corresponding means to modify and perfect this situation.

Table2. Teaching hours of compulsory courses and elective courses.

\begin{tabular}{ccc}
\hline Student absenteeism & Number of student & Proportion (\%) \\
\hline Never absenteeism & 20 & 6.80 \\
occasionally absenteeism & 206 & 70.07 \\
Often absenteeism & 66 & 22.45 \\
Never class & 2 & 0.68 \\
\hline
\end{tabular}

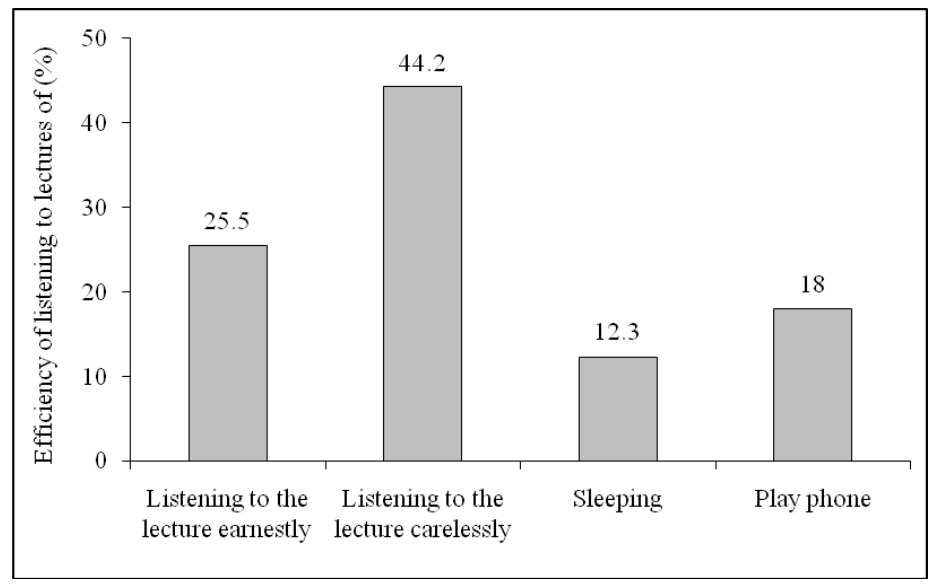

Fig2. Efficiency of listening to lectures of food and drug major students

\section{Teaching Reform Measures for Food and Drug Major}

Food and drug major is characterized by high professional level, high operability and high renewal rate. It's just these three features to determine that the teaching reform of drug and food major should advance with the times and renew continuously. Consequently, we should make reform and innovation for the teaching mode of this major with the development of times.

\section{Arrange Class Period Structure of Course Reasonably}

The reasonable arrangement of course we here mention is the structure, including the combination of class period between theoretical course and practical course. The significances of them are the same [4]. In practice, the class period of practical course always is less than the one of theoretical course. The opportunity of students for operating is few. Their ability of practice is poor. In addition, the class period and the task of experimental course are determined by course teacher generally. It is difficult for experimental course to match with theoretical course due to experimental facilities and other reasons. Consequently, the class periods of experimental course and theoretical course should be arranged reasonably. In this way, students can actively explore the knowledge and ponder a 
problem so as to stimulate their learning interest. Experimental course can improve students' ability of independent inquiry and their actual operating ability while supplementing theoretical course so as to offer a good platform for their future employment. Moreover, an adjustment should be made for compulsory course and optional course. To increase the class period of compulsory course can make students to deeply understand the basic knowledge and the specific function purpose of food major. Meanwhile, the repeated content of compulsory course and compulsory course should be avoided. The reasonable structure for class period of course can change the irritable learning attitude of students. If the same course is lectured separately, even in different classroom, there will be a different attitude. In this way, the enthusiasm of students for class will be stimulated. In addition, their learning efficiency also can be improved.

\section{Strengthen the Construction of Teaching Courseware and Experimental Facilities}

Food and drug major owns a strong practicability and applicability. It is has some epochal character and normalization. In addition, it is the combination of theory and practice. Traditional teaching mode cannot well reflect the feature of drug and food major already. Besides, it cannot meet the new demand of students for teaching. The students' personal demand cannot be reflected, either. To strengthen the construction of classroom teaching courseware and facilities, to make use of multimedia network teaching platform to integrate picture, cartoon, video and representative plant design drawing etc. and make the illustrated lively teaching courseware, and to use network to look up the relevant information at any time can effectively increase the learning interest of students and stimulate their learning enthusiasm [2]. Drug and food major has a strong practicality. Experimental facilities are essential. But according to the investigation, the experimental facility of college is not enough, which has affected the arrangement for class period of experimental course. Students cannot do some experiment personally due to short of experimental facilities. In this case, the experiment is made by the teacher himself/herself, during which the students just watch. Consequently, for students, to increase the experimental facilities is the foundation and precondition to cultivate their learning interest, further comprehend the knowledge of theoretical course, and improve their operating ability.

\section{Do a Good Practical Work of Students}

After graduation, the students will enter the society eventually. Therefore, college plays a crucial role in cultivating the social adjustability of students. Before entering the society, the students must fully understand the knowledge related to drug and food major. Meanwhile, their practical ability, vocational ability and social adjustability also must be cultivated. This means the college should do a good practical work for students during their academic year. The college should establish cooperation project between college and enterprise so as to provide a convenient practical training base. For instance, Lushan College of Guangxi University of Science and Technology established a practice (practical training) base with Guangxi Institute of Medicinal Plant Development in August, 2013, where 32 students from grade-2010 food science and engineering major (food hygiene and inspection field) were arranged to make scientific research. They would complete a 10 -week professional practice and 18-week graduation practice in the institute [3]. In this way, college cooperates with enterprise to make enterprise to participate in the cultivation plan of talents in food major. Undertake a special week practice and group experiment. Assign the specific experimental case to students and require them to complete it independently. Meanwhile, require them to make experimental scheme and process independently. According to the performance of students, the teacher makes an evaluation and gives a mark as the practice grade. In this way, the vocational skill and practical ability of students can be improved [4].

\section{Make Use of Multiple Teaching Platforms to Stimulate Students’ Interest}

Nowadays, WeChat and MicroBlog have been popularized among students. Take full advantage of these internet technologies to combine with micro-lecture and MOOC information platforms so as to establish a new model of interaction between teachers and students. In this way, students can preview their lessons to find out doubt and difficulty so as to stimulate their interest for learning. Meanwhile, 
their learning initiative also can be strengthened. Students can grasp the knowledge and leave message as well as comment to communicate with their teacher on their problems while watching WeChat and MicroBlog [5]. This also can deepen their understanding for the knowledge. This method can become our "second classroom", which can make up for the deficiency that students do not listen carefully in the class to create an out-of-class learning environment. Students' learning interest can be attracted. The informatization of teaching activity and the efficiency of teaching also are improved rapidly.

\section{Summary}

Under the background that new undergraduate colleges are transformed to application-oriented university, the demand of society for compound-applied talents becomes more urgent. To combine specialty attribute and college advantage to make a reform for the counterpart teaching mode is extremely urgent. Food major is a significant industry of the country. The reform and development of teaching mode in drug and food major of higher vocational colleges play an important role in cultivating the various qualities of students, especially for the cultivation of practical operating ability. Meanwhile, it meets the learning demand of students. What's more, it meets the demand of society for talents' cultivation. Consequently, we must proceed from the reality, from students themselves and from colleges themselves to perfect the teaching mode, teaching idea, teaching contents and structure of food major so as to better cultivate students and shape talents as well as bring a better future for the development of food major. In this way, the quality of employment will be improved. Enterprise will give their high evaluation for students and colleges. In addition, the level of college also will be improved.

\section{Acknowledgement}

This research was financially supported by the Teaching Reform Research Project Transformation Research Project of Chongqing University of Education (ZXJG03).

\section{References}

[1] H.T. Sun, F.Y. Wei, X.R. Shao, J. Xu, R.P. Jiang, Reform and practice of enterprise management course system based on food safety management mode, J. Tonghua Nor. Univ. 35 (2014) 63-65. (In Chinese)

[2] X.J. Ma, Discussion on the course "construction of food factory design", Sci. Technol. Innovat. Herald 30 (2012) 192-193. (In Chinese)

[3] J.Y. Cai, J.W. Xiong, Y. Zhang, Study of instrumental analysis teaching of food specialty in independent college, Guangzhou Chem. Ind. 41 (2013) 159-160. (In Chinese)

[4] Y.Q. Su, P. Gong, H. Yu, Y.F. Yang, J.Z. Zhang, Y. Xie, Y. Wang, Y. Xu, Construction of personnel training model and curriculum system of pharmaceutical management and administration, China Pharm. 25 (2014) 3831-3833. (In Chinese)

[5] Y. Xin, X.F. Guo, F.S. Chen, The application of micro course in flipped classroom for food specialty in universities, J. Hunan Univ. Technol. (Soc. Sci.) 11 (2015) 122-125. (In Chinese) 